\title{
A triboelectric energy harvester using human biomechanical motion for low power electronics
}

\author{
KHUSHBOO $^{1}$ and PUNEET AZAD ${ }^{2}$,*(D) \\ ${ }^{1}$ University School of Information, Communication \& Technology, GGSIP University, New Delhi 110078, India \\ ${ }^{2}$ Department of Electronics and Communication Engineering, Maharaja Surajmal Institute of Technology, \\ New Delhi 110058, India \\ *Author for correspondence (puneet.azad@msit.in)
}

MS received 6 September 2018; accepted 31 October 2018; published online 24 April 2019

\begin{abstract}
This article presents the conversion of human biomechanical motion into useful electricity using triboelectricity. Nylon, polytetrafluoroethylene (PTFE) and fluorinated ethylene propylene (FEP) are selected as triboelectric materials for charge generation and aluminium/copper is selected as an electrode during vertical and sliding motions. Output voltage, energy density and power are computed across different capacitors and resistors. The maximum d.c. voltage is found to be 9.56 V across a $1 \mu \mathrm{F}$ capacitor using a combination of nylon and PTFE during vertical motion. Also, the maximum energy density across a $100 \mu \mathrm{F}$ capacitor is $492.47 \mu \mathrm{J} \mathrm{cm}^{-3}$ and the maximum power across a $4.63 \mathrm{M} \Omega$ resistor is $6.2 \mu \mathrm{W}$. Such portable systems can harvest human biomechanical energy while walking or exercising and can act as an infinite lifetime energy source for conventional low power electronics.
\end{abstract}

Keywords. Energy harvesting; PTFE; FEP; sliding motion; vertical motion.

\section{Introduction}

The major concerns of rising pollution, global warming and energy crisis have emerged from the escalated use of non-renewable fuels over the years. The rapid depletion of these resources due to high demand and increasing environment issues has encouraged the use of renewable energy resources, which are effective alternatives for the sustainable development of human civilization [1-3]. The recent development in personal electronics and sensors for the environment, industries, automobiles and healthcare has posed urgent requirements and challenges for the availability of renewable energy resources, thereby relaxing the dependency on limited lifetime batteries. In addition, the trade-offs between their weight and size and lifetime are again a question of concern. Such challenges can be overcome by converting ambient energy into electricity [4-6], which can act as a power source for charging the batteries or directly running the device. Researchers have adopted several techniques, such as piezo/pyroelectricity [7-9], triboelectricity [10-15], thermoelectricity [16], photovoltaic system [17], etc., for the conversion of such energy into useful electricity. The present study is based on triboelectric energy harvesters, which can utilize mechanical energy from human activities, such as walking [18], exercising, finger movements [19], etc., in the environment. Recently, a triboelectric sensor has been developed for the speed measurement and weight detection of vehicles [20]. The concept of triboelectricity is based on charge transfer between two materials due to contact electrification. These charges can be collected via external circuits to generate electricity. Here, we present a triboelectricbased simplified design using polytetrafluoroethylene (PTFE) and fluorinated ethylene propylene (FEP) as triboelectric materials by converting human biomechanical energy, while exercising on a treadmill into useful electricity. The model is implemented in vertical contact separation and lateral sliding mode, which is well-documented in reviews [21]. Several researchers have explored the use of such materials for a wide range of applications. The charge generation between PTFE and nylon has been analysed for different temperatures, which affects the elastic properties of these materials [22]. Also, relative humidity affects the proportionality factor between charge and temperature. A triboelectric nanogenerator (TENG) consisting of FEP and nylon is integrated with an electromagnetic nanogenerator to increase the overall conversion efficiency with a high output voltage and current [23]. Another paper presented a stretchable TENG made from paper and FEP for powering LCD and LEDs [24]. Energy harvesting from human biomechanical energy using PTFE and aluminium as triboelectric materials has been demonstrated to energize multiple LEDs $[25,26]$.

\section{Materials and methods}

We have chosen different combinations of thin films of PTFE, FEP and nylon as triboelectric materials for energy harvesting due to their positions in triboelectric series. PTFE has 

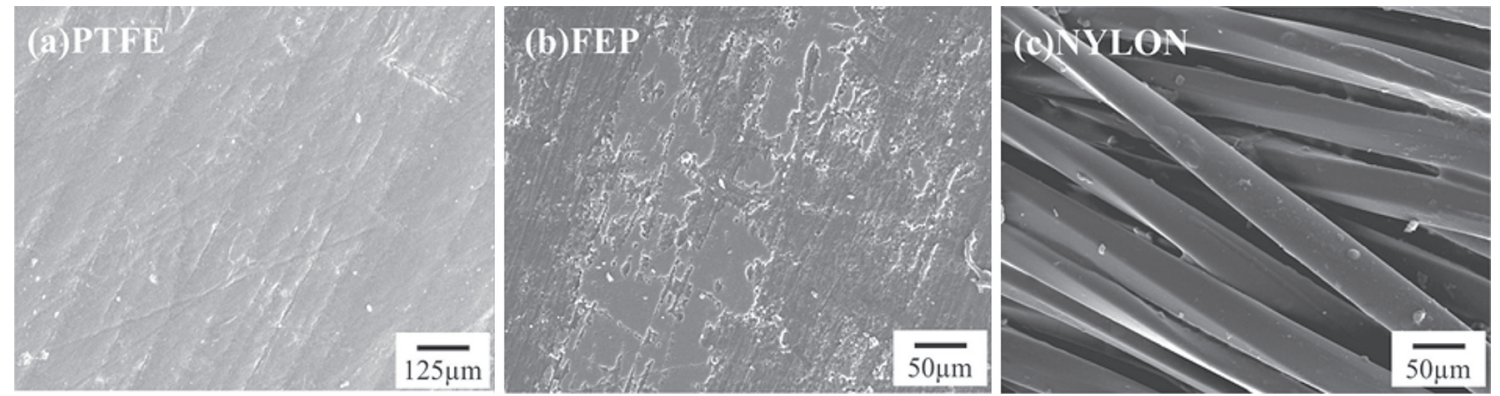

Figure 1. SEM images of (a) PTFE, (b) FEP and (c) nylon.

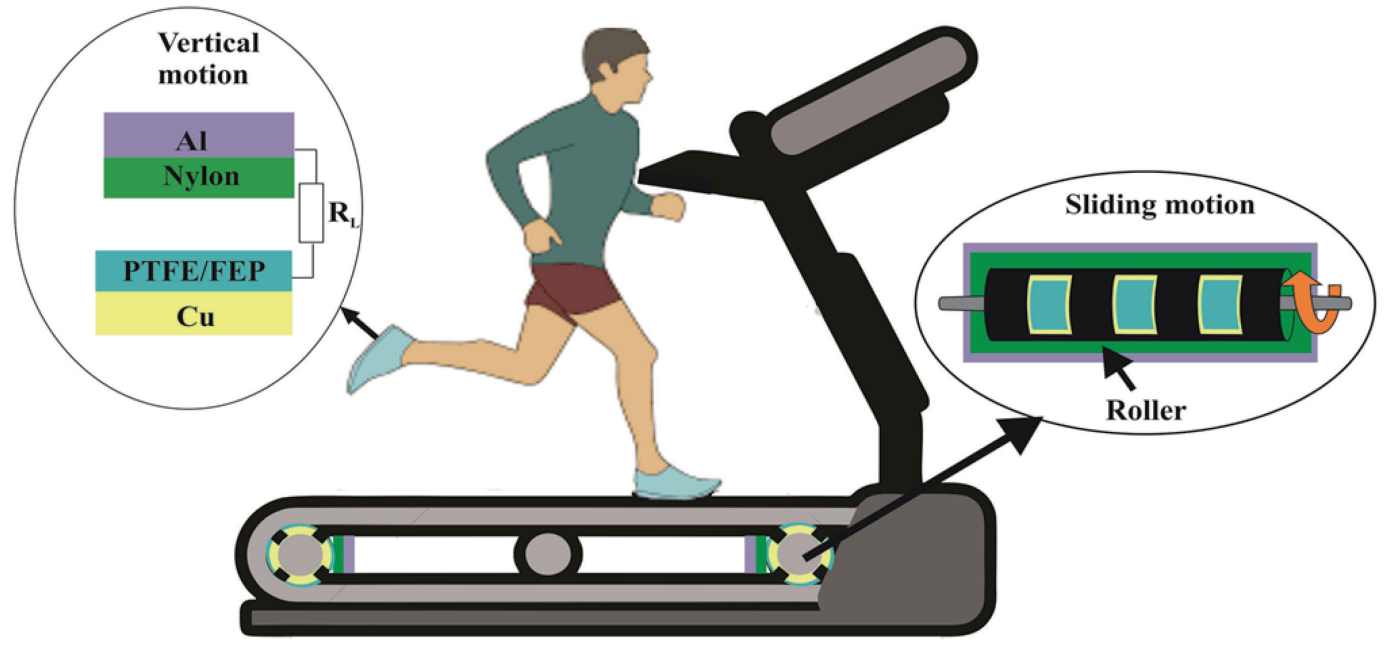

Figure 2. Experimental setup of the triboelectric nanogenerator.

been procured from Dalau Fluoropolymer Products (UK) with a thickness of $125 \mu \mathrm{m}$, FEP from Holscot Fluoroplastics Ltd, UK, having a thickness of $50 \mu \mathrm{m}$ and nylon has been purchased from a local market. Nylon attracts positive charges, while PTFE/FEP has the tendency to attract negative charges. The development of charges during vertical and sliding motion is affected by the surface quality of the films presented by the scanning electron microscopy (SEM) images of PTFE, FEP and nylon as shown in figure 1. The SEM images of all the three materials show regular and evenly distributed microstructures across the entire surfaces. The SEM of nylon shows broadly and regularly distributed patterns demonstrating better capability of retaining charge. This will lead to higher open circuit voltages when it comes in contact with other materials. All the materials are based on polymers exhibiting excellent stability and mechanical robustness, and can operate for several cycles without wear and tear. The triboelectric materials have been arranged in such a fashion that they make frequent contact with each other during the vertical and sliding motions. Figure 2 illustrates a typical TENG for efficiently harvesting human biomechanical energy, while running as vertical motion and rotary motion of the treadmill as sliding motion. Figure 3 presents a similar setup consisting of a d.c. motor, which generates sliding and horizontal motion giving rise to charges on the surface of triboelectric materials. The motor drives a crank and a slider (plate 2) generating a sliding motion as shown in setup I. Plate 1 is further connected to plate 3 in setup-II generating a horizontal motion. Four types of materials including nylon, PTFE/FEP, aluminium and copper are pasted between the plates as shown in figure 3. Such kind of setups may be compared with the sliding motion between the surface and roller of a treadmill and vertical motion due to stepping on the surface while running. $\mathrm{Al}$ and $\mathrm{Cu}$ act as electrodes for collecting positive and negative charges. An external circuit is connected to both the electrodes to store charge in a capacitor. The size of films of each triboelectric material and electrode is $2.5 \mathrm{~cm}$ each and the speed of the motor responsible for vertical and rotary motion is around $200 \mathrm{rpm}$. However, in real applications, vertical motion is due to the person running on the treadmill, while sliding motion is due to the sliding between the roller and surface of treadmill as shown in figure 2. Once these two materials rub each other, the positive and negative charges get deposited on $\mathrm{Al}$ and $\mathrm{Cu}$ films. These charges are extracted 


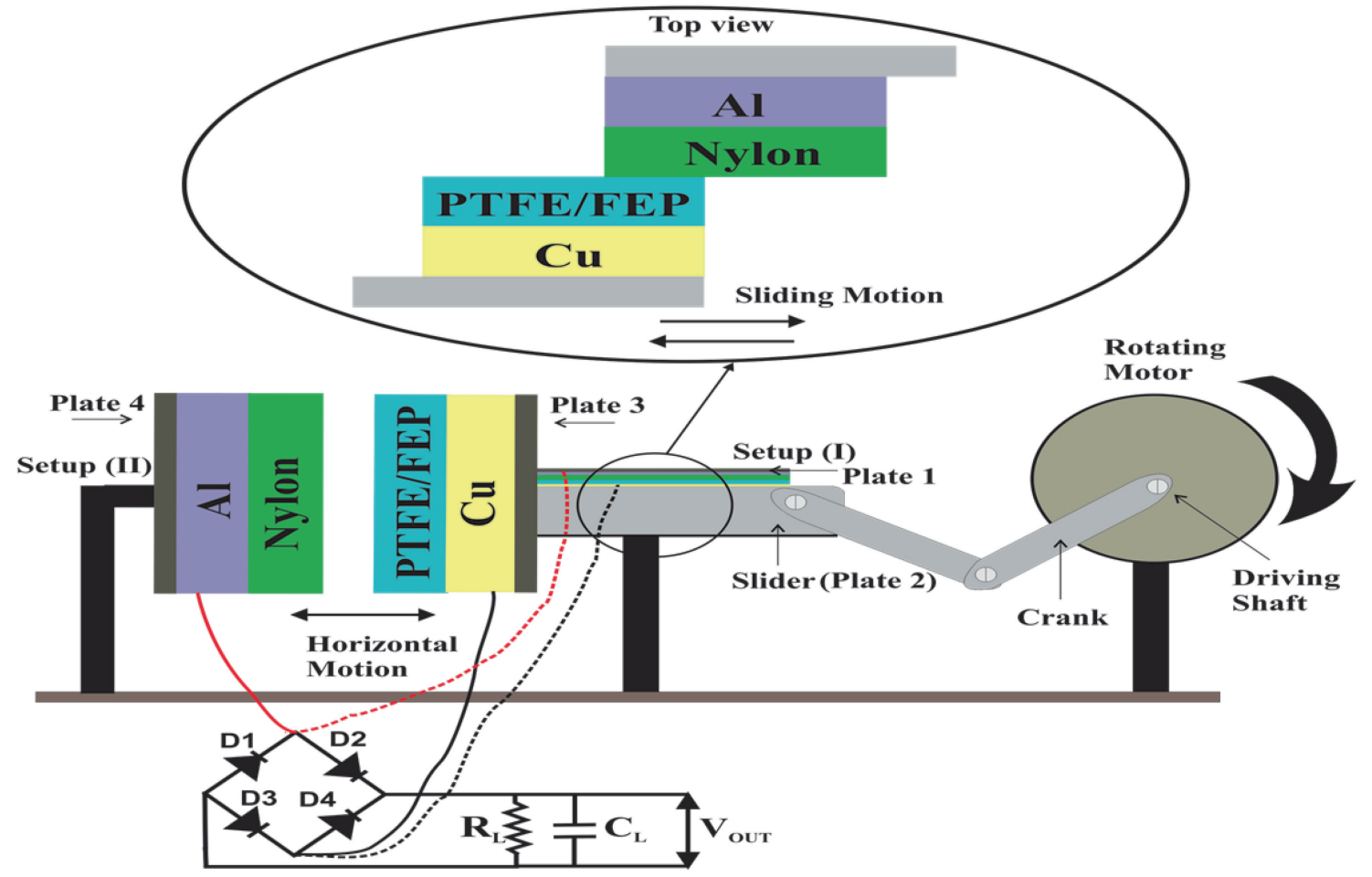

Figure 3. Schematic of energy harvesting during running and rotary motion of the roller.
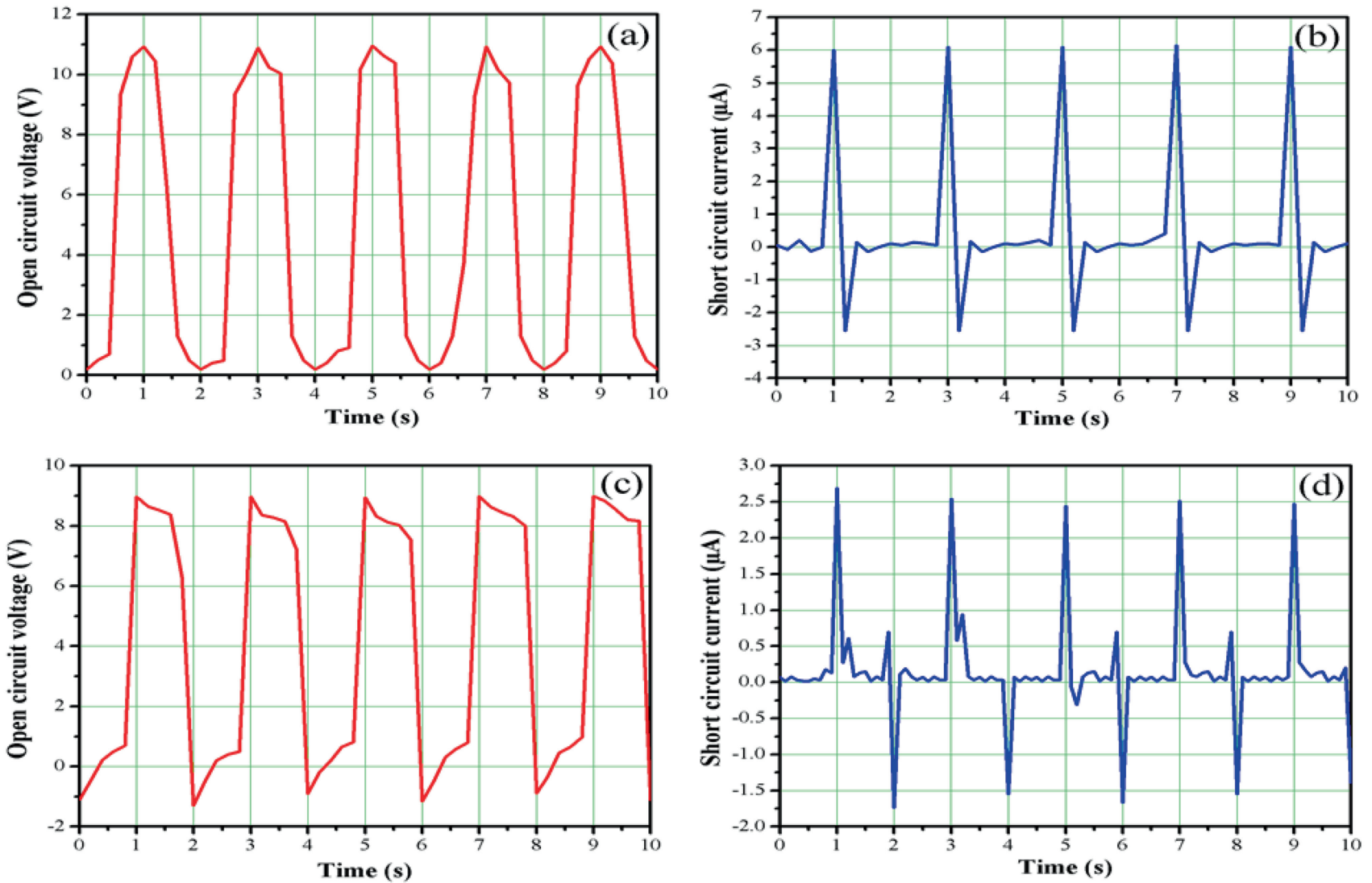

Figure 4. (a) Open circuit voltage for vertical contact mode, (b) short circuit current for vertical contact mode, (c) open circuit voltage for sliding mode and (d) short circuit current for sliding mode using nylon and PTFE. 

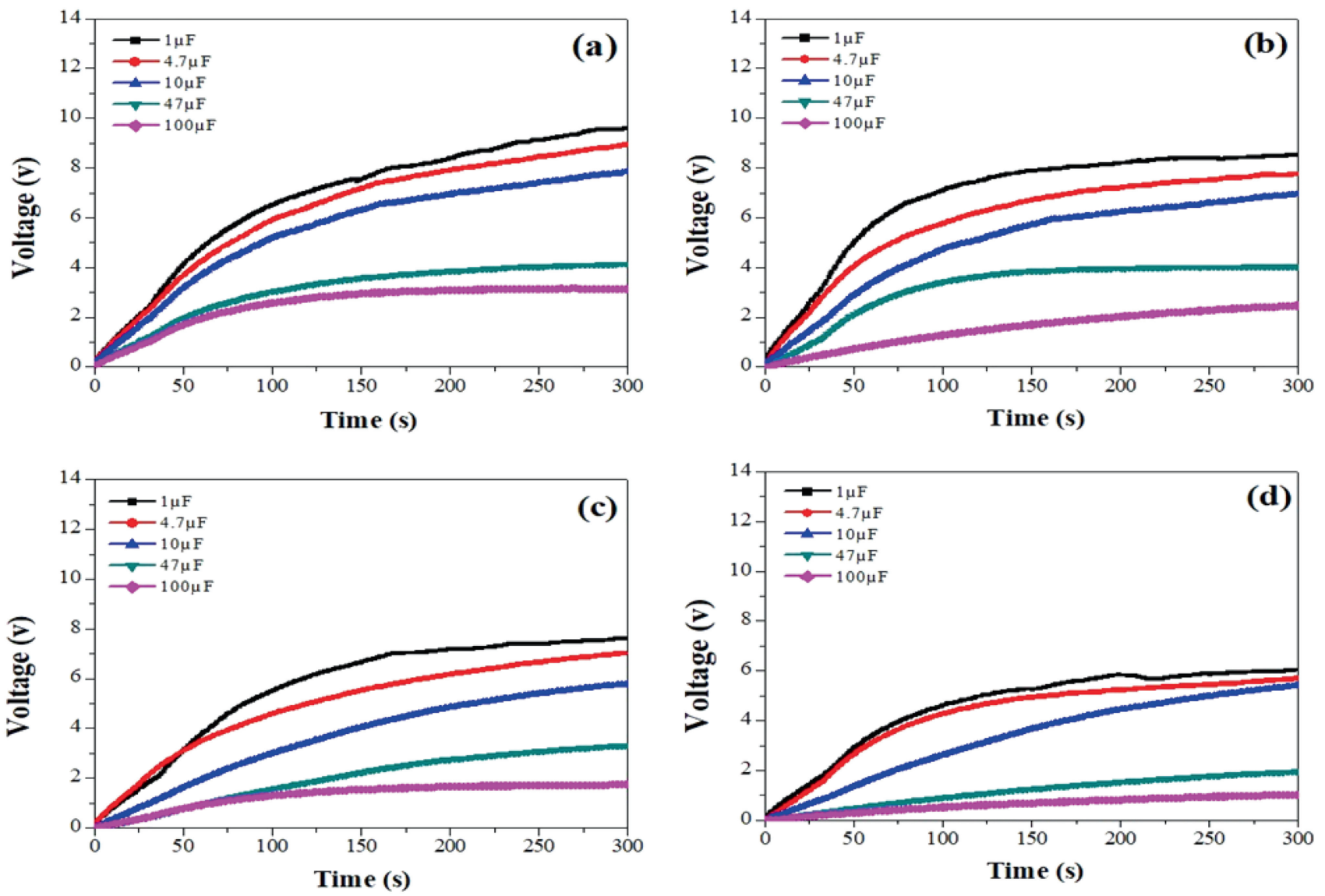

Figure 5. Output voltage across load capacitors for (a) vertical contact mode using nylon and PTFE, (b) vertical contact mode using nylon and FEP, (c) sliding mode using nylon and PTFE and (d) sliding mode using nylon and FEP.

by disengaging the rubbing surfaces using a motor attached to a wheel. The a.c. signal produced by charges is converted to d.c. using a bridge rectifier and a capacitor. The increasing voltage across different capacitors is recorded with time using an electronic logging multimeter (FLUKE 287). Energy density is further calculated across the same capacitors. Power is optimized using different resistors connected across the same capacitors.

The output voltage across a capacitor is given as:

$$
C \frac{\mathrm{d} v}{\mathrm{~d} t}+\frac{V}{R}=I
$$

The stored energy in various capacitors is determined using the equation:

$$
E=\frac{1}{2} C V^{2}
$$

The output power $\left(P_{\text {out }}\right)$ across the resistor load $R_{\mathrm{L}}$ is determined as:

$$
P_{\text {out }}=\frac{V^{2}}{R_{\mathrm{L}}} \text {. }
$$

\section{Results and discussion}

Figure 4 illustrates the open circuit voltage and short circuit current for both vertical and sliding motions generated through TENG using nylon and PTFE as triboelectric materials. The vertical motion generates a maximum voltage and current of $10.95 \mathrm{~V}$ and $6.15 \mu \mathrm{A}$, while the sliding motion generates $8.98 \mathrm{~V}$ and $2.6 \mu \mathrm{A}$. Also, the voltages in both the setups remain above 10 and $8 \mathrm{~V}$ and currents above 6 and $2.5 \mu \mathrm{A}$ for the entire duration. The force during the vertical contact is $3 \mathrm{~N}$. The a.c. signals generated during the sliding and vertical motions are converted into unidirectional signals through a bridge rectifier and the voltages are recorded in different capacitors $(1,4.7,47,10$ and $100 \mu \mathrm{F})$ using an electronic logging multimeter (Fluke 287). The variation of output voltages in a vertical contact and sliding mode across different capacitors is shown in figure 5 using the different combinations of nylon with PTFE and FEP as triboelectric materials. The maximum voltage across the $1 \mu \mathrm{F}$ capacitor is $9.56 \mathrm{~V}$ in $300 \mathrm{~s}$ for the nylon/PTFE combination. Similarly, voltage across 4.7 and $10 \mu \mathrm{F}$ capacitors rises rapidly to 8.94 and $7.84 \mathrm{~V}$. It is observed that the charge is retained for a longer duration in bigger capacitors than small ones. It is also illustrated in 

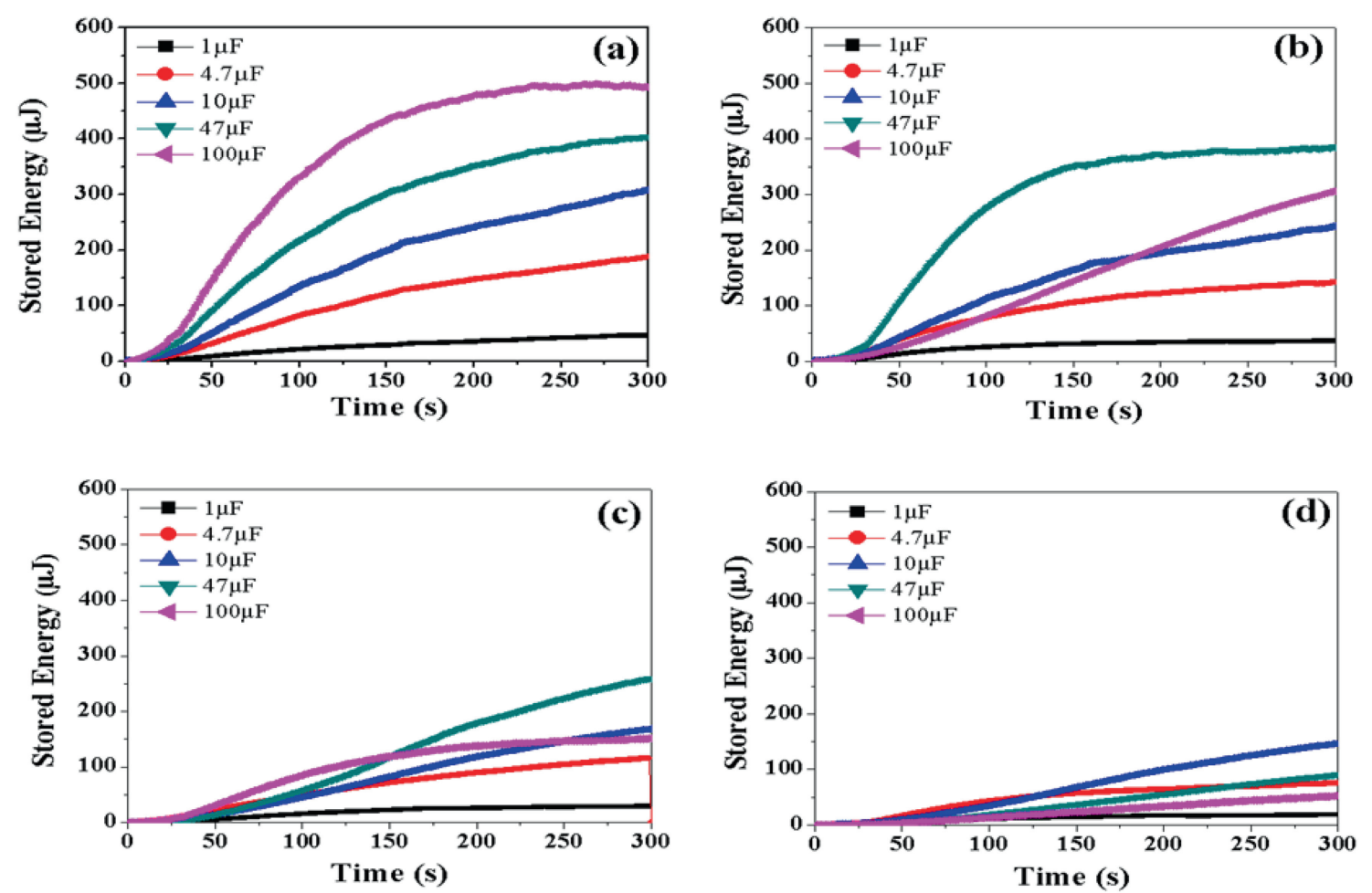

Figure 6. Stored energy for different load capacitors for (a) vertical contact mode using nylon and PTFE, (b) vertical contact mode using nylon and FEP, (c) sliding mode using nylon and PTFE and (d) sliding mode using nylon and FEP.

Table 1. Maximum output voltage and energy using different combinations.

\begin{tabular}{|c|c|c|c|c|c|c|c|c|}
\hline \multirow[b]{2}{*}{ Capacitance $(\mu \mathrm{F})$} & \multicolumn{2}{|c|}{$\begin{array}{l}\text { Vertical mode using } \\
\text { nylon + PTFE }\end{array}$} & \multicolumn{2}{|c|}{$\begin{array}{l}\text { Vertical mode using } \\
\text { nylon + FEP }\end{array}$} & \multicolumn{2}{|c|}{$\begin{array}{l}\text { Sliding mode using } \\
\text { nylon + PTFE }\end{array}$} & \multicolumn{2}{|c|}{$\begin{array}{l}\text { Sliding mode using } \\
\text { nylon + FEP }\end{array}$} \\
\hline & $V_{\mathrm{DC}}(\mathrm{V})$ & Energy $(\mu \mathrm{J})$ & $V_{\mathrm{DC}}(\mathrm{V})$ & Energy $(\mu \mathrm{J})$ & $V_{\mathrm{DC}}(\mathrm{V})$ & Energy $(\mu \mathrm{J})$ & $V_{\mathrm{DC}}(\mathrm{V})$ & Energy $(\mu \mathrm{J})$ \\
\hline 1 & 9.56 & 45.75 & 8.53 & 36.38 & 7.61 & 29.02 & 6.03 & 18.20 \\
\hline 4.7 & 8.94 & 187.82 & 7.76 & 141.52 & 7.01 & 115.80 & 5.68 & 75.85 \\
\hline 10 & 7.84 & 307.32 & 6.95 & 242.03 & 5.77 & 167.17 & 5.40 & 145.96 \\
\hline 47 & 4.14 & 404.43 & 4.05 & 385.51 & 3.32 & 259.49 & 1.97 & 91.28 \\
\hline 100 & 3.13 & 492.47 & 2.47 & 306.75 & 1.73 & 151.48 & 1.02 & 52.32 \\
\hline
\end{tabular}

figure 5 that the small capacitors attain higher voltages and saturation due to a smaller time constant. Also, the combination of nylon with PTFE in vertical contact mode produces the best results out of the four combinations. The maximum voltages across a $1 \mu \mathrm{F}$ capacitor in vertical mode using nylon and FEP and sliding mode using nylon and PTFE are 8.53 and $7.61 \mathrm{~V}$, respectively. Figure 6 presents the stored energy with respect to time in different capacitors according to equation (2). The maximum stored energy density across a 100 $\mu \mathrm{F}$ capacitor is found to be $492.47 \mu \mathrm{J} \mathrm{cm}^{-3}$. It is observed that the amount of energy stored in small capacitors is less due to their lower charge storage capacity. Here again, the combination of nylon with PTFE in vertical contact mode has generated the maximum energy out of the four combinations. A comparative table of voltage and energy is presented in table 1.

Furthermore, the electric power is estimated by connecting different load resistors (4.63 10.44 and 21.15 M $\Omega$ ) across different load capacitors $(1,4.7,10,47$ and $100 \mu \mathrm{F})$ as shown in figure 7. It is observed that the maximum output power of $6.2 \mu \mathrm{W}$ is observed across $4.63 \mathrm{M} \Omega$ and $1 \mu \mathrm{F}$ load capacitor resistors when nylon and PTFE are used as triboelectric materials during vertical motion. This is due to the fact that charges are more uniformly distributed in vertical motion in both the triboelectric materials (nylon and PTFE). Furthermore, it is shown that the maximum power is observed across 

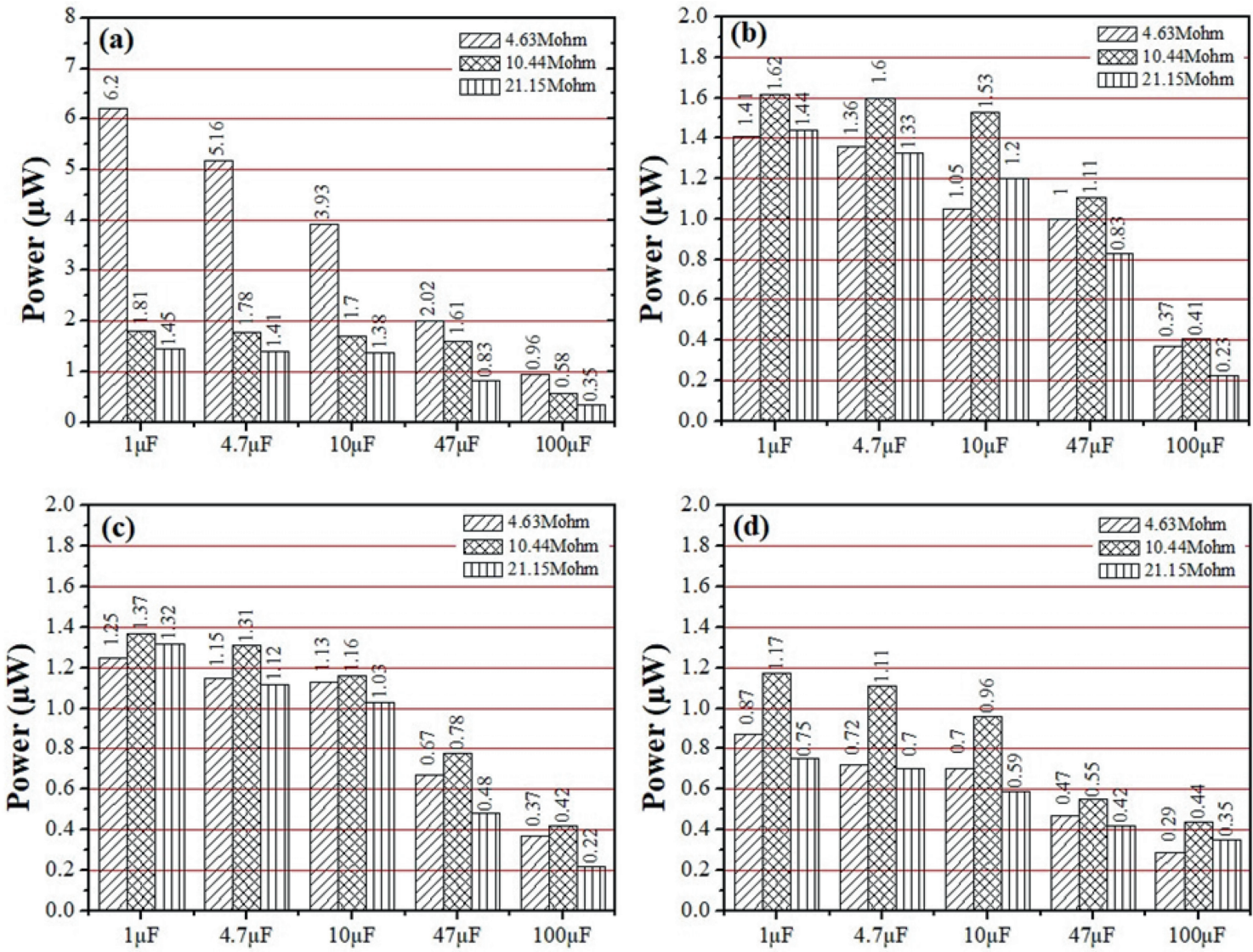

Figure 7. Output power across different load capacitors using (a) vertical contact mode with nylon and PTFE, (b) vertical contact mode with nylon and FEP, (c) sliding mode with nylon and PTFE and (d) sliding mode with nylon and FEP.

Table 2. Comparative analysis of the maximum power output for various load resistors $(\mathrm{M} \Omega)$ and load capacitors ( $\mu \mathrm{F})$ for different combinations.

\begin{tabular}{|c|c|c|c|c|c|c|}
\hline \multirow[b]{3}{*}{ Capacitance $(\mu F)$} & \multicolumn{5}{|c|}{ Maximum power output $(\mu \mathrm{W})$} & \\
\hline & \multicolumn{3}{|c|}{ Vertical mode using nylon + PTFE } & \multicolumn{3}{|c|}{ Vertical mode using nylon + FEP } \\
\hline & $4.63 \mathrm{M} \Omega$ & $10.44 \mathrm{M} \Omega$ & $21.15 \mathrm{M} \Omega$ & $4.63 \mathrm{M} \Omega$ & $10.44 \mathrm{M} \Omega$ & $21.15 \mathrm{M} \Omega$ \\
\hline 1 & 6.2 & 1.81 & 1.45 & 1.41 & 1.62 & 1.44 \\
\hline 4.7 & 5.16 & 1.78 & 1.41 & 1.36 & 1.60 & 1.33 \\
\hline 10 & 3.93 & 1.7 & 1.38 & 1.05 & 1.53 & 1.2 \\
\hline 47 & 2.02 & 1.61 & 0.83 & 1.00 & 1.11 & 0.83 \\
\hline 100 & 0.96 & 0.58 & 0.35 & 0.37 & 0.41 & 0.23 \\
\hline \multicolumn{7}{|c|}{ Maximum power output $(\mu \mathrm{W})$} \\
\hline & \multicolumn{3}{|c|}{ Sliding mode using nylon + PTFE } & \multicolumn{3}{|c|}{ Sliding mode using nylon + FEP } \\
\hline Capacitance $(\mu \mathrm{F})$ & $4.63 \mathrm{M} \Omega$ & $10.44 \mathrm{M} \Omega$ & $21.15 \mathrm{M} \Omega$ & $4.63 \mathrm{M} \Omega$ & $10.44 \mathrm{M} \Omega$ & $21.15 \mathrm{M} \Omega$ \\
\hline 1 & 1.25 & 1.37 & 1.32 & 0.87 & 1.17 & 0.75 \\
\hline 4.7 & 1.15 & 1.31 & 1.12 & 0.72 & 1.11 & 0.7 \\
\hline 10 & 1.13 & 1.16 & 1.03 & 0.7 & 0.96 & 0.59 \\
\hline 47 & 0.67 & 0.78 & 0.48 & 0.47 & 0.55 & 0.42 \\
\hline 100 & 0.37 & 0.42 & 0.22 & 0.29 & 0.44 & 0.35 \\
\hline
\end{tabular}


$1 \mu \mathrm{F}$ in all the four modes, while it decreases with the increasing

values of capacitances. Also, $4.63 \mathrm{M} \Omega$ resistance in the first mode and $10 \mathrm{M} \Omega$ in rest of the three modes are found to be the most suitable resistances across all capacitors as shown in table 2. This study shows the potential of human biomechanical motion specially during walking or running using triboelectric phenomenon-based harvesters.

\section{Conclusions}

In this paper, different combinations of triboelectric materials are used for energy harvesting using vertical and sliding motions. This approach demonstrates the conversion of human biomechanical energy into electricity with a maximum output power up to $6.2 \mu \mathrm{W}$ across a $1 \mu \mathrm{F}$ load capacitor and a $4.63 \mathrm{M} \Omega$ resistor in vertical contact separation mode using nylon and PTFE as triboelectric materials. It is observed that a maximum of $9.56 \mathrm{~V}$ is obtained across a $1 \mu \mathrm{F}$ capacitor in $300 \mathrm{~s}$ with subsequent reduction in output voltage with an increase in capacitance. Also, the maximum stored energy of $492.47 \mu \mathrm{J} \mathrm{cm}^{-3}$ is found across a $100 \mu \mathrm{F}$ capacitor. It is demonstrated that the maximum power is obtained across a particular load resistance, which further decreases with a higher value of resistances.

\section{References}

[1] Economou A 2010 Renew. Sustain. Energy Rev. 141496

[2] Stigka E K, Paravantis J A and Giouli K M 2014 Renew. Sustain. Energy Rev. 32100

[3] Ellabban O, Abu-Rub H and Blaabjerg F 2014 Renew. Sustain. Energy Rev. 39748

[4] Paradiso J A and Starner T 2005 IEEE Pervasive Comput. 418

[5] Qi Y and McAlppine M 2010 Energy Environ. Sci. 31275
[6] Gao F, Li W, Wang X, Fang X and Ma M 2016 Nano Energy 22 19

[7] Shin Y H, Jung I, Noh M S, Kim J H, Choi J Y, Kim S et al 2018 Appl. Energy 216741

[8] Azad P, Singh V P and Vaish R 2018 J. Electron. Mater. 47 4721

[9] Sharma M, Singh V P, Singh S, Azad P, Ilahi B and Madhar N A 2018 J. Electron. Mater. 474882

[10] Azad P and Vaish R 2017 EPJ Plus 132253

[11] Chaudhary P and Azad P 2018 IETE J. Res., https://doi.org/ 10.1080/03772063.2018.1530074

[12] Yadav D and Azad P 2017 Proceedings of International Conference on Computing, Communication and Automation (ICCCA) p 1493

[13] Niu S, Wang X, Yi F, Zhou Y S and Wang Z L 2015 Nat. Commun. 68975

[14] Khushboo and Azad P 2017 Proceedings of International Conference on Computing, Communication and Automation (ICCCA) p 1499

[15] Chaudhary P and Azad P 2017 Proceedings of International Conference on Computing, Communication and Automation (ICCCA) p 1483

[16] Carlson E J, Strunz K and Otis B P 2010 IEEE J. Solid-State Circuits $\mathbf{4 5} 741$

[17] Singh G K 2013 Energy 531

[18] Donelan J M, Li Q, Naing V, Hoffer J A, Weber D J and Kuo A D 2008 Science 319807

[19] Zhong J, Zhong Q, Fanb F, Zhang Y, Wang S, Hua B et al 2013 Nano Energy 2491

[20] Yadav D and Azad P 2018 IET Intell. Transp. Sys. 12958

[21] Wang Z L, Chen J and Lin L 2015 Energy Environ. Sci. 82250

[22] Kleyman G, Kang T, Twiefel J and Voit W 2018 Energy Harvest. Syst. 41

[23] Quan T, Wang Z L and Yang Y 2016 App. Mater. Interfaces 8 19573

[24] Wu C, Wang X, Lin L, Guo H and Wang Z L 2016 ACS Nano 10 4652

[25] Bai P, Zhu G, Lin Z H, Jing Q, Chen J, Zhang G et al 2013 ACS Nano 73713

[26] Zhu G, Bai P, Chen J and Wang Z L 2013 Nano Energy 2688 